張宪武韓静淑 单慰會

郑鴻元 柴 明

(中国科学院林業土虽研究所)

1957 年 8 月 12 日

[1] J. E. Fuller and L. F. Rettger, Soil Science, 31, 219-234,(1931).

[2] J. E. Greaves, L. Jones and A. Anderson, Soil science, 49, 9-19(1940).

[ 3 ] C.K. Horner and F. E. Allison, J. Bact., 47, 1-14 (1944).

[4] P. W. Wilson, J. F. Hull and R. H. Burris, Proco Natl. Acad. Sci. U. S., 29, 289(1943).

[5] М. В. Фөцров, Микробиология, Т. 17, Стр. 425 (1948).

[6] М. В. Федров, Биологическая Фиксация Азота Атмосферы, Сөльхозгиз, Москва, 1952.

\section{棉花黄萎病發生及 潛育期研究简报}

棉花黃萎病在我国东北、华北、西北等地重点棉 区早已先后發生，近几年来抹且逐年寡延加重。关于 此病的分布被生和为害情况，各地区有关单位亦會进 行調查，所得結果大致相同。但是在对于苗期是否發 病, 还存在着不同看法, 文献中也說法紛云。我們會 椫进行了試驗（于1955 年 5 月 18 日播种), 結果如下 表:

\begin{tabular}{|c|c|c|c|c|c|c|c|}
\hline \multirow[b]{2}{*}{ 处 } & \multicolumn{2}{|c|}{ 接 } & \multicolumn{2}{|c|}{ 球 } & 房 & \multicolumn{2}{|l|}{$(\%)$} \\
\hline & 月 & 日 & \begin{tabular}{|l|l|} 
目 & 日 \\
\end{tabular} & $\left|\frac{1}{7}\right| \frac{6}{4}$ & $\left|\frac{9}{7}\right| \frac{\theta}{7} \mid$ & \begin{tabular}{|l|l|} 
日 & 至 \\
7 & 23 \\
\end{tabular} & \begin{tabular}{|l|l|} 
& $\frac{\text { 日 }}{7}$ \\
\end{tabular} \\
\hline 播种时土譔挠种 & & 18 & $\ldots$ & 一 & 0.90 & 0.90 & 2.70 \\
\hline 、 $2-3$ 片具叶土瀷接种 & & 14 & - & - & - & 0.92 & 3.10 \\
\hline 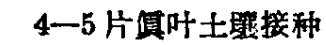 & & 23 & - & - & - & - & 0.97 \\
\hline 6-7片笑叶土琵接种 & 7 & 4 & - & - & - & - & 1.01 \\
\hline 2-3 片真叶案刺接种 & 6 & 14 & 51.49 & 59.41 & 61.39 & 49.50 & 50.50 \\
\hline 4-5 片面叶综刺接种 & & 23 & 一 & $\longrightarrow$ & 35.45 & 40.91 & 41.82 \\
\hline 6-7片军叶综刺接种 & 7 & 4 & - & - & 4.85 & 67.96 & 65.05 \\
\hline 对 照 & - & -1 & 一 & $一$ & $\longrightarrow$ & 一 & 一 \\
\hline
\end{tabular}

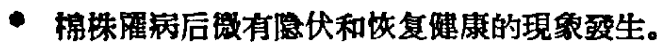

試驗証明，当环境条件适合时（主要是温度），棉 株虽在苗期（2-3 片资叶）亦能發生黃萎病，而潜育 期的长短，件随环境条件的轉变而轉变。一般在伤口 侵入的情况下，潜育期通常为 8-14 天。但至 6-7 片 员叶以后，因温度逐激升高而發病也最快。潜育期可 樎短为 3 天（黃萎适宜温度一般为 $22-24^{\circ} \mathrm{C}$ )。而士 壤接种的处理, 多在接种的 1-2个月內才开始大量
病，而罯病的棉株也为数懒少。

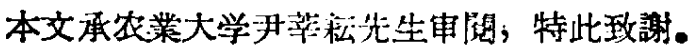
耿 殿 棨

(东北农業科学的究所辽陽棉作嚗)

1957 年 7 月 3 日

\section{白云鄂博区域地質简报}

白云鄂博区位于包头正北 145 公里。該区主要是

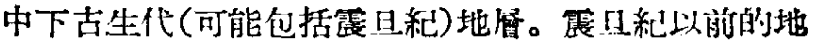

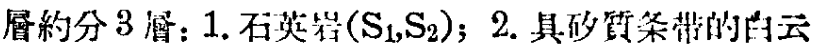

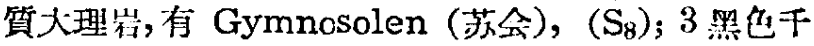
枚岩、石英岩、变質灰岩等互恰 $\left(\mathrm{S}_{3}\right)$ 。此系地情很可

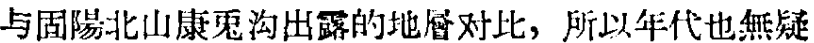

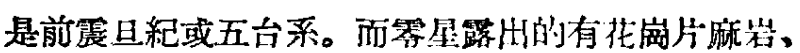
片麻岩、角閃片岩等, 他們可与除川所产的对比, 年 代当为桑干系或太古代。白云山脉主姴的地詹是: 1:石 英岩 $\left(\mathrm{S}_{4}\right)$, 可能盖有黑板岩和石英竹的互層 $\left(\mathrm{S}_{5}\right) ; 2$.

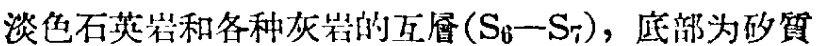
条带的白云質灰岩, 中上部为黑色䟚質灰岩, 越上越

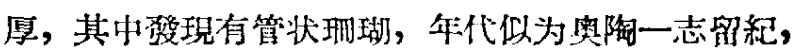
而石英岩只見于中下部，越上越少; 3. 細粒石英岩， 炭質石英岩和板岩的互層 $\left(\mathrm{S}_{9}\right)$ ，在有些地方跟線出片

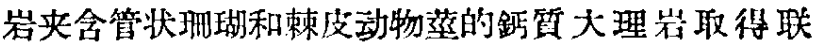
系, 所以此層的年代也似为奥陶一志留紀。这一大系 地居, 厚約几千公尺以上, 很像是游相地槽沉积, 可 惜沼有發現真正的寒武紀和奥隐紀的化不，所以对他 認識还不够完全。在泊云山脉北带有合很多化石的石

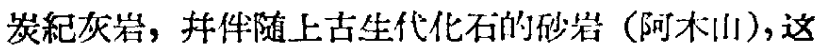
些真正的上古生代地層, 不但不厚, 抹且汥有变啠, 而灰岩的稍微变質只能涗明遭受动力作用，因为找不 着跟花風岩的关系。在这化带的南部, 还有一些砂岩 夹砾岩，或綠或紅，未找着化石，植物碎㕍不易愁定， 所以他的年代，可能是上古生代或中生代，但决不是 新生代。在此区域成片的新生代地畨非常少見，因此 就不多叙。

关于岩浆活动, 主要的有两期: 前霞旦紀和中下 古生代。在前震旦紀, 主要是粒状花崗岩, 在隐川非: 常常見，在白云山脉中，常遭挤压，珄随其他地何，

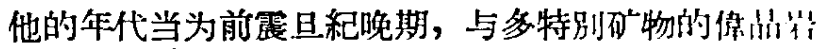

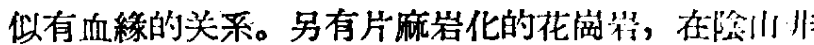
常常見, 似为最老的花崗岩 (太古生?)，在白云山川 只成断塊而已。在中下古生代，有很大的嗔㹲安川栄 系，噴發时期似与綠色片岩很接近，也有很大的超焦 性岩侵入，現已蛇紋岩化，而造成鉄矿的热液毫無疑 义地是它带来的，因为矿化的白云筫大理岩、蛇粒 
岩、磁鉄矿等都是生长在一起, 扑且北、闹被中下古生 代花菵岩所侵入。而多筌石、多稀土金渴的原因，与

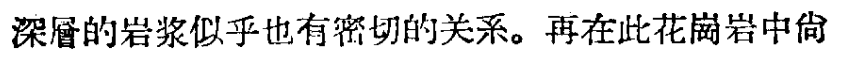
有很多閃石閃长岩的俘㨜体, 可能与超些性岩也有关 系。在白云山脉南部到处都有大片的黑云母花南岩,

明显地侵入到中下古生代地層內, 可是在石炭紀和以 后的砂岩內汥有花摛岩和接触变質的源迹 (阿木山与 他接触的是前震旦紀花崗岩)。另外还有不少脉岩, 年 代有早有晚, 获不鳌叙, 然而值得提及的是在固陽西北 有大片类似白型紀的噴登流紋岩和中新世的䒺武岩。

关于热液作用, 主要的是白云鄂博类型的热液交 代鉄矿朱，上文已經提及与超基性岩有关，所以就不 再叙。

至于該区的地賈构浩, 白云山脉, 根据地㕌、岩 浆活动、热液作用等表明有显著的加里东运动, 因此 白云山脉的地質可以代表陰山山脉以北的地質, 抹且 可以跟祁連门对比，也可以說是葍繞在中华地盾外方 的地槽带。这样, 白云川脉和陰山山脉之間地带是中 华地盾和蒙古高原南部加里东地槽的分界綫, 两区地 質的發展大有区别。应当注意的是, 海西宁运动以及 以后各期的运动虽然都有表現, 可是岩浆活动抹不很 显著。

楊傑吕德徽刘萧光薛宪租 (中国科学院地質研究所)

1957 年 8 月 8 日

\section{填充床層的不稳定傳热}

填充床居的不稳定傳热，对操作的控制，以及研 究与此相类似的热風嘘等的机理, 有重要的意义。作 者对一沿有化学反应的圆杜形填充休屡进行了研究。 由热量衡算, 得到其微分方程为。

$$
\begin{gathered}
K_{e}\left(\frac{\partial^{2} T}{\partial r^{2}}+\frac{1}{r} \frac{\partial T}{\partial r}\right)-C_{g} G \frac{\partial T}{\partial x}=\epsilon C_{g} \rho_{g} \frac{\partial T}{\partial \tau} \\
+C_{s} \rho_{s} \frac{\partial t_{s}}{\partial \tau}(1-\epsilon) \\
h_{v}\left(T-t_{s}\right)=C_{s} \rho_{s}(1-\epsilon) \frac{\partial t_{s}}{\partial \tau}
\end{gathered}
$$

边值条件: (1) $\tau=0$ 时, $t_{s}=t_{0}$; (2) $X=0$ 时, $T=T_{03}$ (3) $r=R$ 时, $h_{v}\left(T-t_{c}\right)=-K_{e}\left(\frac{\partial T}{\partial r}\right)_{r=R_{0}}$ 。

式中: $T$ 及 $t_{s}$ 分別为流体及固体填充物的温度, $t_{c}$ 为管壁的鼬度, $C_{g}$ 及 $C_{s}$ 为流体及固体的比热, $\rho_{g}$ 及 $\rho_{s}$ 为流体及固体的密度, $K_{c}$ 为床屏的有效导热系 数, $G$ 为流体的質量速度, $\epsilon$ 为塻充物的空隐率, $\tau$ 为 时間, $X 、 r$ 为床居中任意一点之縱座标及牛徑, $R$ 为 床層的牛徑, $h_{v}$ 为流体与填充物間的体积給热系数, $h_{w}$ 为管壁的薄膜給热系数。Amundson[1] 曾用数 分析方法, 求得上述方程組的解答。

$$
\begin{aligned}
& T=2 E\left(T_{0}-t_{c}\right) \psi_{c}(U, V) \sum_{n=1}^{\infty} \frac{\epsilon^{-F 3_{n}^{2} U} J_{0}\left(S_{\xi_{n}}\right)}{\left(E^{2}+\xi_{n}^{2}\right) J_{0}\left(\xi_{n}\right)} \\
& +2 E\left(t_{0}-t_{c}\right) \sum_{n=1}^{\infty} \psi\left(V_{n} U,-\frac{V}{V_{n}}\right) \frac{\frac{-F \xi_{n} V}{V}}{V_{n}^{n} J_{0}\left(S_{5}^{\xi_{n}}\right)}+t_{c} \\
& t_{s}=2 E\left(T_{0}-t_{c}\right) \psi(U, V) \sum_{n=1}^{\infty} \frac{\epsilon^{-F t_{n}^{2} U} J_{0}\left(S \xi_{n}\right)}{\left(E^{2}+\xi_{n}^{2}\right) J_{0}\left(\xi_{n}\right)} \\
& +2 E\left(t_{0}-t_{c}\right) \sum_{n=1}^{\infty} v_{c}\left(V_{V_{n}}^{-}, U V_{n}\right) \frac{\frac{-V F 3_{n}^{2}}{V_{n}}}{\left(E^{2}+\xi_{n}^{2}\right)} J_{0}\left(\frac{\left.S \xi_{n}\right)}{\left.\xi_{n}\right)}+t_{c}\right.
\end{aligned}
$$

式中各符号的意义部見原文。

作者进行了实驗, 以驗証 Amundson 計算的 結果, 实瞼是在管徑为 81 㲤米, 以直洏 0.0132 毫米 的玻璃球为填充物的填充休層中进行的。傅热介質是 空气，其質量流速 $G=3090$ 千克 $/$ 米 $^{2}$ 时。边值条件 $T_{0}=180^{\circ} \mathrm{C}, t_{s}=20^{\circ} \mathrm{C}, t_{0}=17^{\circ} \mathrm{C}$ 。在术層出口一端 測定徑向各点温度随时閏变化的关系。其結果如圖 1 , 圖中各曲綫表示計算的結果, 各个点表示实驗的实測 值。其中有效导热系数 $K_{e}$, 边界給热系数及填光物的 空吵紋根据朱葆琳等所获得的公式計算[?][3]。 $h_{c}$ 煳据 Hougen 和 Wilker 的公式計算[4], $h_{v}$ 則由 $h_{c}$ 按下 式換算:

$$
h_{v}=\frac{3(1-\epsilon)}{r_{p}} h
$$

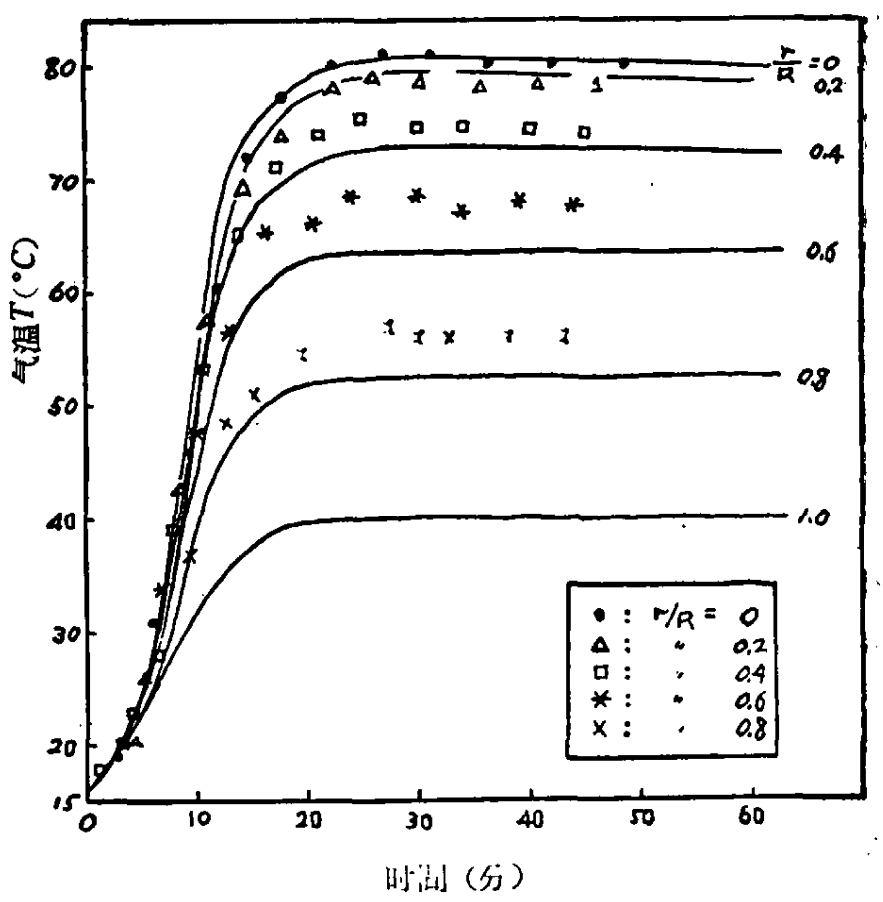

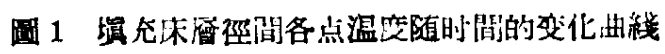
点一一实駱值 曲綫——計算值 